\title{
Off-pump coronary surgery: Effect on early mortality and stroke
}

\author{
Wen Cheng, MD \\ Timothy A. Denton, MD \\ Gregory P. Fontana, MD \\ Sharo Raissi, MD \\ Carlos Blanche, MD \\ Robert M. Kass, MD \\ Kathy E. Magliato, MD \\ James Mirocha, MS \\ Alfredo Trento, MD
}

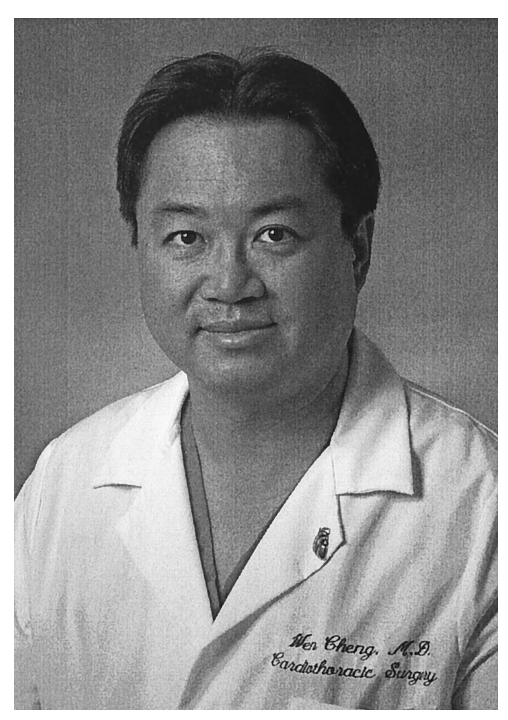

Dr Cheng

From the Division of Cardiothoracic Surgery, Cedars-Sinai Medical Center, Los Angeles, Calif.

Presented at the Seventh Annual Meeting "Cardiothoracic Techniques and Technology" 2001, New Orleans, La, Jan 25, 2001.

Received for publication July 6, 2001; revisions requested Aug 28, 2001; revisions received Oct 24, 2001; accepted for publication Dec 10, 2001.

Address for reprints: Wen Cheng, MD, Department of Cardiothoracic Surgery, Cedars-Sinai Medical Center, 8700 Beverly Blvd, Suite 6215, Los Angeles, CA 90048 (E-mail: chengw@cshs.org).

J Thorac Cardiovasc Surg 2002;124:313-20

Copyright (C) 2002 by The American Association for Thoracic Surgery

0022-5223/2002 $\$ 35.00+0 \quad \mathbf{1 2 / 1 / 1 2 2 3 0 4}$

doi:10.1067/mtc.2002.122304
Background: Avoiding cardiopulmonary bypass in coronary artery bypass grafting is thought to reduce early mortality and morbidity.

Methods: We used our prospective database to compare all patients having offpump coronary surgery $(\mathrm{n}=389)$ with those having on-pump coronary surgery $(\mathrm{n}=2412)$ between March 15, 1995, and November 1, 2000. Patients were grouped by age (years) in decades $(>90,80-89,70-79,60-69,<60$ years). The Northern New England risk model was applied. Thirty-two independent variables were entered into a stepwise logistic regression analysis with the end points being surgical mortality and postoperative stroke.

Results: Patients undergoing off-pump operations were older $(70.9 \pm 12$ vs $68.1 \pm$ 11 years; $P<.001$ ), and their Northern New England predicted risk was higher $(11.9 \% \pm 13 \%$ vs $9.2 \% \pm 10 \% ; P<.001)$. However, patients having on-pump bypass had significantly more bypass grafts constructed $(3.3 \pm 0.8$ vs $1.9 \pm 0.8 ; P$ $<.001)$ and triple-vessel coronary artery disease $(58 \%$ vs $28 \% ; P<.001)$. There were no significant differences in postoperative mortality, stroke rate, complications, and length of stay between the groups. Logistic regression analysis did not show that cardiopulmonary bypass was a risk factor for either surgical mortality (odds ratio, 1.08; $P=.83$ ) or stroke (odds ratio, $1.59 ; P=.27$ ).

Conclusion: Off-pump coronary bypass did not reduce early mortality and morbidity. Early and late results should be compared in a prospective randomized study.

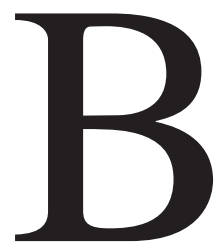

eating-heart surgery was originally the only approach to myocardial revascularization. ${ }^{1}$ In 1967 , Kolessov ${ }^{2}$ reported a left internal thoracic artery (LITA) to left anterior descending (LAD) coronary artery anastomosis through a left thoracotomy on a beating heart, as a method of treatment for angina pectoris. However, this was quickly abandoned in favor of coronary artery bypass grafting $(\mathrm{CABG})$ via median sternotomy with modern cardiopulmonary bypass $(\mathrm{CPB})$ techniques because of the improved safety and ease of suturing on a still, bloodless field.

Off-pump coronary surgery (OPCAB) has been reintroduced in the past few years and now accounts for nearly $20 \%$ of all CABG operations performed in the United States. ${ }^{1}$ This is despite the lack of prospective randomized studies documenting proven mortality or morbidity benefits in the short or long term.

Cardiac surgeons endure less favorable operative exposure, safety, and a steep learning curve to perform arterial bypass grafting on a "beating" heart because of the 
belief that avoiding CPB improves end organ function by diminishing microembolic activation of inflammatory cascades and mechanical trauma to blood elements.

\section{Patients and Methods}

Between March 15, 1995, and November 1, 2000, 2801 patients had isolated CABG with 389 patients having OPCAB, 368 via a median sternotomy and 21 through a small anterior thoracotomy. Another 2412 patients had on-pump CABG. All patients' data were entered into our cardiac surgical database, which follows 576 preoperative, intraoperative, and postoperative variables. Patients were grouped by age (years) in decades ( $>90,80-89,70-79$, $60-69$, and $<60$ years). The Northern New England (NNE) risk model was used to predict surgical mortality. ${ }^{3}$

\section{Statistical Analysis}

Results for continuous variables are expressed as mean \pm standard deviation. Results for categorical variables are expressed as number (percent). The Student $t$ test for independent samples was used to determine statistically significant differences between the 2 groups for the continuous variables. The $\chi^{2}$ test was used to determine statistically significant group differences for the categorical variables. Stepwise logistic regression was used to select the predictor variables for the outcomes surgical mortality and postoperative cerebrovascular accident (CVA). (See the appendix for the list of potential predictor variables that were considered). The final logistic regression models included only those variables that were significant in the stepwise logistic regression models. In the final models, the independent variables are expressed as odds ratios with $95 \%$ confidence intervals, and the corresponding $P$ value is also given. An $\alpha$ level of .05 was used to determine statistical significance. Statistical calculations were performed by means of SAS version 8.1 (SAS Institute, Cary, NC).

Incomplete revascularization was derived by comparing significantly obstructed coronary arteries at cardiac catheterization with coronary arteries surgically grafted. Nongrafting of any significantly obstructed coronary artery was considered an incomplete revascularization. Grafting of all diseased vessels was considered complete revascularization.

\section{Learning Curve}

All operations involved 2 surgeons, as surgeon and first assistant surgeon, who performed the proximal and distal anastomoses. The 6 surgeons, present during the entire period of the study, participated in a minimum of 95 to a maximum of 149 cases. There was a gradual adoption of off-pump techniques with $3.5 \%$ of OPCABs performed in $1996,9 \%$ in $1997,15.2 \%$ in $1998,28.1 \%$ in 1999 , and $26.4 \%$ in 2000.

\section{Patient Selection}

The choice of OPCAB versus on-pump CABG was surgeon preference. Factors favoring $\mathrm{OPCAB}$ included patients with suitable anatomy, epicardial target vessels $1 \mathrm{~mm}$ or larger, which were noncalcified and easy to expose, patients considered at high risk for $\mathrm{CPB}$, elderly patients with multiple preoperative morbidities, and especially patients with significant calcification of the ascending aorta and vascular disease.
Contraindications to OPCAB included technical issues such as small, calcified, intramyocardial coronary targets. Difficulty in vessel exposure and unstable condition of the patient also precluded an off-pump approach.

Four hospitals were used by the group with $90 \%$ of all cases at Cedars-Sinai Medical Center.

\section{Surgical Technique}

OPCAB. A median sternotomy or small anterior thoracotomy (minimally invasive direct coronary artery bypass, MIDCAB) was used. For the small anterior thoracotomy, internal thoracic artery (ITA) harvest was with one of two specialized retractors (LIMA lift; Cardiothoracic Systems, Inc, Cupertino, Calif, or Thoralift, United States Surgical Corp, Norwalk, Conn). Proximal and distal coronary artery flow was controlled with silicone rubber loops (Retract-O-Tape; Quest, Allen, Tex). Blood was cleared from the anastomotic site with a commercial carbon dioxide saline-blower (Clearview blower/mister kit; Medtronic, Inc, Minneapolis, Minn). Commercial stabilizers included suction stabilizers (Medtronic Octopus I and II; Medtronic, Inc) and U-shaped foot stabilizers (Universal Stabilizer System; Estech Systems, Inc, Danville, Calif). A heparin dose of 10,000 units was given before vessel occlusion, and the activated clotting time (ACT) was maintained at twice control ACT. Heparin was fully reversed before sternal closure.

We selectively used coronary shunts (Flo-Thru intraluminal shunt; Bio-Vascular, Inc, St Paul, Minn), primarily in constructing bypass grafts to dominant right coronary arteries. Exposure for lateral and inferior wall vessels was achieved by a combination of deep pericardial stitches, an opening of the right side of the pericardium to the inferior vena cava-right atrial junction, and a right decubitus Trendelenberg position. Proximal anastomoses were made to the ascending aorta with the systolic blood pressure between 70 to $80 \mathrm{~mm} \mathrm{Hg}$ and a curved vascular clamp. If significant aortic calcification precluded safe clamp placement, proximal anastomoses were made to the side of the ITA.

\section{Conventional CABG}

CABG was performed through a median sternotomy under moderate hypothermia $\left(28^{\circ} \mathrm{C}-32^{\circ} \mathrm{C}\right)$ and $\mathrm{CPB}$ support. Single-dose, antegrade, cold blood cardioplegia was supplemented with cold continuous retrograde crystalloid cardioplegia and topical iced slush to protect the myocardium. Proximal anastomoses were performed during a single period of aortic crossclamping. The CPB circuit consists of a roller pump (Jostra Bentley Corp, Irvine, Calif) and membrane oxygenator (Avecor Affinity, Medtronic, Inc). Both OPCAB and on-pump CABG patients were discharged receiving either aspirin or warfarin sodium (Coumadin) if their heart rhythm was atrial fibrillation.

\section{Results}

The OPCAB patients were significantly older $(70.9 \pm 12$ years vs $68.1 \pm 11$ years; $P<.001)$ than on-pump CABG patients (Table 1). There were more 90-year-old patients (11 vs 5) and a greater percentage of 80 -year-old patients $(20.7 \%$ vs $11.4 \% ; P<.05)$ in the OPCAB group. The $\mathrm{OPCAB}$ patients tended to be more urgent in acuity level 
TABLE 1. Patient clinical characteristics

\begin{tabular}{|c|c|c|c|}
\hline Characteristic & $\begin{array}{c}\text { OPCAB } \\
(\mathbf{n}=\mathbf{3 8 9})\end{array}$ & $\begin{array}{c}\text { On-pump } \\
(n=2412)\end{array}$ & $P$ value \\
\hline \multicolumn{4}{|l|}{ Age (y) } \\
\hline Mean & $70.9 \pm 12$ & $68.1 \pm 11$ & $<.001$ \\
\hline$\geq 90$ & $11(2.9)$ & $5(0.2)$ & \\
\hline $80-89$ & 81 (20.7) & 275 (11.4) & \\
\hline $70-79$ & $134(34.5)$ & $914(37.9)$ & \\
\hline $60-69$ & 91 (23.3) & $673(27.9)$ & \\
\hline$<60$ & 72 (18.6) & $545(22.6)$ & \\
\hline Male & $279(71.6)$ & $1815(75.3)$ & .165 \\
\hline LVEF(\%) & $54 \pm 13$ & $53 \pm 14$ & .150 \\
\hline \multicolumn{4}{|l|}{ Acuity } \\
\hline Elective & $254(65.4)$ & $1734(71.9)$ & .005 \\
\hline Urgent & $116(29.8)$ & $523(21.7)$ & \\
\hline Emergency & $17(4.3)$ & $142(5.9)$ & \\
\hline \multicolumn{4}{|l|}{ Angina CCS } \\
\hline I & (7.4) & $(10.2)$ & .002 \\
\hline II & $(28.9)$ & $(31.0)$ & \\
\hline III & $(38.4)$ & (27.6) & \\
\hline IV & $(25.4)$ & (31.2) & \\
\hline \multicolumn{4}{|l|}{ NNE risk (\%) } \\
\hline \multicolumn{4}{|l|}{ Age (y) } \\
\hline Mean & $11.9 \pm 13$ & $9.2 \pm 10$ & $<.001$ \\
\hline$\geq 90$ & $31.2 \pm 23$ & $21.7 \pm 12$ & NS \\
\hline $80-89$ & $20.3 \pm 14$ & $19.8 \pm 14$ & NS \\
\hline $70-79$ & $14.0 \pm 13$ & $11.5 \pm 9$ & .004 \\
\hline $60-69$ & $6.0 \pm 6$ & $6.5 \pm 6$ & NS \\
\hline$<60$ & $2.6 \pm 3$ & $3.1 \pm 4$ & NS \\
\hline
\end{tabular}

Variables are expressed as mean \pm SD or $\mathrm{n}(\%)$. CCS, Canadian classification system; $L V E F$, left ventricular ejection fraction; $N N E$, Northern New England; $N S$, not significant.

$(29.8 \%$ vs $21.7 \% ; P<.05)$. Their anginal symptoms tended to be more severe (Canadian Cardiovascular Society class III or IV, $63.8 \%$ vs $58.8 \% ; P<.05)$. Their overall predicted risk by the NNE risk model was significantly greater $(11.9 \%$ $\pm 13 \%$ vs $9.2 \% \pm 10 \% ; P<.001)$.

This increased predicted risk in OPCAB patients is reflected in a comparison of preoperative risk factors (Table 2). Prior carotid endarterectomy $(7.5 \%$ vs $4 \% ; P=.002)$, chronic obstructive pulmonary disease $(14.7 \%$ vs $11.3 \% ; P$ $<.05)$, creatinine concentration more than $2.0 \mathrm{mg} / \mathrm{dL}(8.6 \%$ vs $5.2 \% ; P=.008$ ), symptoms of congestive heart failure $(17.5 \%$ vs $13.7 \% ; P<.05)$, and peripheral vascular disease (26.2\% vs. $19.7 \% ; P=.003$ ) were all more prevalent in OPCAB patients. On-pump CABG patients had a higher incidence of cigarette use $(51.6 \%$ vs $45.8 \% ; P=.03)$, diabetes $(31.7 \%$ vs $24.7 \%$; $P=.006)$, and previous myocardial infarction $(35.9 \%$ vs $29.2 \% ; P=.01)$.

However, on-pump patients differed significantly from the OPCAB patients in the extent of their preoperative coronary artery disease (CAD) and the number and location of coronary arteries bypassed (Tables 3 and 4). On-pump CABG patients had significantly more triple-vessel CAD $(58 \%$ vs $28 \% ; P<.001)$ and less single-vessel CAD $(11 \%$
TABLE 2. Preoperative risk factors

\begin{tabular}{lccc}
\hline Variable & OPCAB & On-pump & $\boldsymbol{P}$ value \\
\hline Prior surgery & $35(9.0)$ & $284(11.8)$ & NS \\
CEA & $29(7.5)$ & $96(4.0)$ & .002 \\
CVA & $41(10.5)$ & $211(8.8)$ & NS \\
Cigarettes & $178(45.8)$ & $1245(51.6)$ & .03 \\
COPD & $57(14.7)$ & $273(11.3)$ & .05 \\
DM & $96(24.7)$ & $763(31.7)$ & .006 \\
HTN & $237(60.9)$ & $1490(61.8)$ & NS \\
Creatinine $>2.0 \mathrm{mg} / \mathrm{dL}$ & $31(8.6)$ & $124(5.2)$ & .008 \\
PVD & $102(26.2)$ & $474(19.7)$ & .003 \\
MI & $115(29.2)$ & $865(35.9)$ & .01 \\
CHF & $68(17.5)$ & $331(13.7)$ & .05 \\
LVEF $<30 \%$ & $24(6.8)$ & $196(8.3)$ & $\mathrm{NS}$ \\
LM & $(30.0)$ & $(28.6)$ & $\mathrm{NS}$ \\
\hline
\end{tabular}

Variables are expressed as $\mathrm{n}(\%)$. CEA, Carotid endarterectomy; CHF, congestive heart failure; $C O P D$, chronic obstructive pulmonary disease; CVA, cerebral vascular accident; DM, diabetes mellitus; HTN, hypertension; $L M$, left main coronary; $L V E F<30 \%$, left ventricular ejection fraction less than $30 \%$; $M I$, myocardial infarction; NS, not significant; PVD, peripheral vascular disease.

TABLE 3. Number of distal anastomoses and diseased vessels

\begin{tabular}{llll}
\hline Variable & OPCAB & On-pump & $P$ value \\
\hline Distal anastomosis (No.) & & & \\
$\quad$ Age (y) & & & \\
$\quad$ Mean & $1.9 \pm 0.8$ & $3.3 \pm 0.8$ & $<.001$ \\
$\geq 90$ & $1.2 \pm 0.9$ & $2.8 \pm 0.4$ & \\
$80-89$ & $2.0 \pm 0.7$ & $3.1 \pm 0.7$ & \\
$70-79$ & $1.9 \pm 0.8$ & $3.3 \pm 0.7$ & \\
$60-69$ & $1.9 \pm 0.9$ & $3.4 \pm 0.9$ & \\
$<60$ & $1.9 \pm 0.8$ & $3.4 \pm 0.8$ & \\
Diseased vessels (\%) & & & \\
1 VD & 33 & 11 & $<.001$ \\
2 VD & 38 & 31 & \\
3 VD & 28 & 58 & \\
Incomplete revascularization (\%) & 28.5 & 14.6 & $<.001$
\end{tabular}

Variables are expressed as mean \pm SD or $\mathrm{n}(\%) .1 \mathrm{VD}$, One-vessel disease; $2 V D$, two-vessel disease; $3 V D$, three-vessel disease.

vs $33 \% ; P<.001)$. As a result, they received more bypass grafts ( 3.3 vs $1.9 ; P<.001$ ), which was consistent in all age groups. However, LITA and radial artery use was not different, with right internal thoracic artery (RITA) use showing a modest increase $(18.3 \%$ vs $12.4 \% ; P=.005)$ in on-pump CABG patients. There were significant differences in location of coronary arteries grafted, with circumflex and posterior descending coronary arteries more commonly grafted in the on-pump CABG patients.

Revascularization was incomplete significantly more often in the OPCAB patients than in the on-pump CABG group $(28.5 \%$ vs $14.6 \% ; P<.001)$. Surgical mortality was $2.5 \%$ when the revascularization was complete versus $3.0 \%$ when incomplete $(P=.5)$. Postoperative CVA was $2.3 \%$ 
TABLE 4. Arterial conduits and arteries bypassed

\begin{tabular}{lccc}
\hline Variable & OPCAB & On-pump & $\boldsymbol{P}$ value \\
\hline ITA & & & \\
$\quad$ Overall & $368(94.7)$ & $2303(95.5)$ & NS \\
LITA & $355(91.3)$ & $2228(92.4)$ & NS \\
$\quad$ RITA & $48(12.4)$ & $441(18.3)$ & .005 \\
Radial artery & $114(29.2)$ & $760(31.5)$ & NS \\
Coronary artery anastomosis & & & \\
$\quad$ LAD & $356(91.5)$ & $2303(95.5)$ & .001 \\
Diagonal & $80(20.5)$ & $943(39.1)$ & $<.001$ \\
PDA & $55(14.1)$ & $1345(55.8)$ & $<.001$ \\
Circumflex & $202(51.9)$ & $2119(87.9)$ & $<.001$ \\
RCA & $112(29)$ & $676(28)$ & NS \\
Intermediate & $15(4)$ & $376(16)$ & $<.001$
\end{tabular}

Variables are expressed as $\mathrm{n}(\%)$. ITA, Internal thoracic artery; $L A D$, left anterior descending; LITA, left internal thoracic artery; $N S$, not significant; $P D A$, posterior descending artery; $R C A$, right coronary artery; RITA, right internal thoracic artery.

versus $2.2 \%(P=.89)$ when comparing complete with incomplete revascularization. Surgical mortality before and after 1999 was $2.5 \%$ versus $2.7 \%(P=.71)$. Postoperative CVA before and after 1999 was $2.3 \%$ versus $2.5 \%(P=$ $.66)$.

Increased age, creatinine concentration greater than 2.0 $\mathrm{mg} / \mathrm{dL}$, ejection fraction less than $30 \%$, prior CABG, increased New York Heart Association class, acute myocardial infarction, and increased surgical acuity were found to be independent variables increasing surgical mortality. Disease of the LAD vessel was found to decrease surgical mortality. Increased age, surgical acuity, creatinine level greater than $2.0 \mathrm{mg} / \mathrm{dL}$, and presence of peripheral vascular disease were found to increase the incidence of postoperative CVA. However CPB did not increase either surgical mortality or postoperative CVA (Table 6).

There were no significant differences in mortality between the groups overall or by age in decades (Table 5). Incidence of stroke, likewise, was not significantly different. Of note, there were no strokes in the OPCAB patients who were octogenarians, but there were 5 in the septuagenarian group. Neither group, however, was significantly different from their same-decade on-pump CABG peers. Of the 12 deaths in the OPCAB group, 5 died of cardiac related events, including arrhythmias, pump failure, and myocardial infarction. One died of a stroke, 3 died of small bowel necrosis, and 3 died of sepsis resulting from pneumonia or intravascular catheters.

New atrial fibrillation, reoperation for bleeding, deep sternal infection, sepsis, prolonged intubation, and readmission within 6 weeks were not significantly different between groups (Table 7). Twelve-hour postoperative blood loss and any blood product usage were not different. New dialysis was slightly more prevalent in the OPCAB group, but the difference was small. Not surprisingly, the percentage of
TABLE 5. Postoperative complications

\begin{tabular}{lcrc}
\hline Variable & OPCAB & On-pump & $\boldsymbol{P}$ value \\
\hline Surgical mortality & & & \\
Age (y) & & & \\
Overall & $12(3.1)$ & $60(2.5)$ & NS \\
$\geq 90$ & $3(27.3)$ & $0(0.0)$ & NS \\
$80-89$ & $6(7.7)$ & $14(5.1)$ & NS \\
$70-79$ & $2(1.5)$ & $22(2.4)$ & NS \\
$60-69$ & $1(1.1)$ & $16(2.4)$ & NS \\
$<60$ & $0(0.0)$ & $7(1.3)$ & NS \\
CVA & & & \\
Age (y) & $7(1.8)$ & $55(2.3)$ & NS \\
Overall & $1(9.1)$ & $0(0.0)$ & NS \\
$\geq 90$ & $0(0.0)$ & $7(2.6)$ & NS \\
$80-89$ & $5(3.9)$ & $31(3.4)$ & NS \\
$70-79$ & $1(1.1)$ & $13(1.9)$ & NS \\
$60-69$ & $0(0.0)$ & $5(0.9)$ & NS \\
$<60$ & & &
\end{tabular}

Variables are expressed as $\mathrm{n}(\%)$. CVA, Cerebrovascular accident; NS, not significant.

OPCAB patients with no complications (72\%) closely matched the on-pump CABG patients (70\%). Overall postoperative length of stay was not different between OPCAB and on-pump CABG patients. However, OPCAB patients less than 60 years old had a shorter length of stay than on-pump patients ( $4.9 \pm 2.2$ days vs $6.2 \pm 4$ days; $P=.02)$, and septuagenarians in the on-pump group had a shorter length of stay than the off-pump group. Note, this is the only group, when examined by decade, in which the off-pump patients were at significantly higher risk than the on-pump patients.

\section{Discussion}

Conventional coronary surgery through a median sternotomy with CPB support is the standard for myocardial revascularization. Having a clear, still operative field enabled the widespread adoption of cardiac surgical techniques for both myocardial revascularization and valvular replacement and repair under "safe" conditions. However, the introduction of less invasive catheter-based techniques and the general aging of the population has forced cardiac surgeons to apply cardiac surgical techniques to an increasingly older and sicker population. ${ }^{4,5}$

Tuman and associates ${ }^{6}$ reported that the risk of endorgan dysfunction in patients having isolated on-pump CABG increased exponentially with age. Patients 65 years of age and younger had a low incidence of neurologic events $(<1 \%)$, but patients older than 75 years had a 9 -fold increase $(8.9 \%)$. However, cardiac related morbidity, such as low cardiac output and postoperative myocardial infarction, was unrelated to advanced age in the stepwise logistic regression analysis. They forecast that the use of coronary revascularization techniques without extracorporeal circula- 
TABLE 6. Results of logistic regression

\begin{tabular}{|c|c|c|c|c|c|c|}
\hline \multirow[b]{2}{*}{ Risk factors } & \multicolumn{3}{|c|}{ Surgical mortality } & \multicolumn{3}{|c|}{ CVA } \\
\hline & OR & $95 \% \mathrm{CL}$ & $P$ value & OR & $95 \% \mathrm{CL}$ & $P$ value \\
\hline Age (continuous) & 1.05 & $(1.03-1.08)$ & .001 & 1.04 & $(1.01-1.07)$ & .009 \\
\hline Creatinine $\geq 2.0 \mathrm{mg} / \mathrm{dL}$ & 3.02 & (1.56-5.83) & .001 & 2.52 & $(1.23-5.18)$ & .012 \\
\hline $\mathrm{EF} \leq 30 \%$ & 2.18 & (1.16-4.09) & .015 & & & \\
\hline Prior CABG & 2.29 & $(1.22-4.29)$ & .010 & & & \\
\hline NYHA class & 1.27 & (1.07-1.51) & .006 & & & \\
\hline MI, this & 2.2 & $(1.28-3.79)$ & .005 & & & \\
\hline Surgical acuity & 1.98 & $(1.44-2.72)$ & .001 & 1.94 & $(1.41-2.69)$ & .001 \\
\hline Cath LAD & 0.36 & $(0.20-0.65)$ & .001 & & & \\
\hline PVD & & & & 2.42 & $(1.42-4.10)$ & .001 \\
\hline CPB & 1.08 & $(0.54-2.17)$ & .830 & 1.59 & $(0.70-3.57)$ & .267 \\
\hline
\end{tabular}

$C A B G$, Coronary artery bypass grafting; Cath $L A D$, cardiac catheterization, left anterior descending coronary artery disease; $C L$, confidence limits; $C P B$, cardiopulmonary bypass; $E F$, ejection fraction; $M I$, this, myocardial infarction, this admission; NYHA class, New York Heart Association classification; $O R$, odds ratio; $P V D$, peripheral vascular disease.

tion or aortic crossclamping may decrease the neurologic risk of CABG. ${ }^{7,8}$ Several groups in South America and the United States reported good results with OPCAB in the early and middle 1990s.9-11 However, it was not until the introduction of increasingly sophisticated mechanical stabilizers that OPCAB enjoyed a renaissance. Presently, despite the lack of any long-term, prospectively randomized studies to prove the benefit of beating-heart surgery, nearly $20 \%$ of patients in the United States are undergoing myocardial revascularization without $\mathrm{CPB}$ support. ${ }^{1}$ Among cardiac surgeons, the argument is increasingly not whether patients should have beating-heart surgery, but why all patients are not having beating-heart surgery.

Our series of 389 patients represents a selective use of beating-heart techniques in our cardiac surgical population. It is a retrospective, nonrandomized experience and includes all patients having only myocardial revascularization by our group during a 5-year period. Our beating-heart surgery patients were significantly older, with a higher percentage of patients aged 80 years and older than our on-pump patients. There are 2 comparable series of octogenarians having OPCAB. The Washington Hospital Center experience differs in that they report a total of 71 patients over a 12-year period from January 1987 to May 1999. ${ }^{12}$ Thirty-four percent of the patients underwent an anterior thoracotomy approach to single-vessel off-pump CABG (MIDCAB). Among our series of 81 octogenarians and 11 nonagenarians, only 2 patients had an anterior thoracotomy approach. Their operative mortality $(6 \%)$ and postoperative length of stay ( $9 \pm 6$ days) for octogenarians was similar to our results $(7.7 \%$ mortality and $8.6 \pm 4.5$ days, length of stay).

A more comparable series is the experience of Ricci and associates $^{13}$ in octogenarians. They compared 97 OPCAB patients with 172 conventional CABG patients from January 1995 to May 1999. They report a variety of surgical approaches (median sternotomy, left anterior small thoracotomy, left posterior thoracotomy, and subxiphoid access), although they favored median sternotomy to obtain complete myocardial revascularization. Our 81 OPCAB octogenarians were compared with 275 octogenarians having conventional on-pump CABG. Average number of bypass grafts of OPCAB patients between our series and theirs was similar (2.0 vs 1.8), as was the number having conventional CABG (3.1 vs 3.3 grafts per patient). Their reported mortality was higher than ours $(10.3 \%$ vs $7.7 \%)$ for OPCAB but was similar for on-pump CABG (5.2\% vs 5.1\%). We found no difference in risk profile between our off-pump and on-pump octogenarian CABG patients. As in their series, we report no episode of stroke in our octogenarians. However, we did not find a significant difference in stroke rate compared with our conventional CABG patients. This is due to the low incidence of stroke seen in our on-pump CABG patients overall $(2.3 \%)$, and in our on-pump octogenarian patients $(2.6 \%)$. They reported a significant reduction in stroke rate as their conventional $\mathrm{CABG}$ patients had a stroke rate of $9.3 \%$. They also reviewed angiographic data to determine the severity and distribution of CAD. They observed an important trend to more extensive multivessel involvement in the CPB cohort. They speculate that this may explain the difference in graft-patient ratio observed between the CPB cohort (3.3) compared with the off-pump cohort (1.8). We also found a trend toward significantly more extensive CAD in our on-pump patients. The presence of triple-vessel CAD was twice as often seen in the onpump group (58\%) versus the off-pump group (28\%). This explains the fewer grafts per patient seen in the OPCAB (2.0) versus on-pump patients (3.1). This is also consistent with the less frequent lateral and inferior wall bypass grafts seen in our OPCAB patients when compared with our on-pump CABG patients.

Arom and colleagues ${ }^{14}$ also noted this difference of 
TABLE 7. Postoperative complications

\begin{tabular}{|c|c|c|c|}
\hline Variable & OPCAB & On-pump & $P$ value \\
\hline \multirow{2}{*}{\multicolumn{4}{|c|}{$\begin{array}{l}\text { Postop LOS (d) } \\
\text { Age (y) }\end{array}$}} \\
\hline $\begin{array}{l}\text { Age (y) } \\
\text { Overall }\end{array}$ & & & \\
\hline$\geq 90$ & $9.6 \pm 5.4$ & $10.8 \pm 4.7$ & NS \\
\hline $80-89$ & $8.6 \pm 4.5$ & $9.3 \pm 7.4$ & NS \\
\hline $70-79$ & $9.5 \pm 7.7$ & $7.8 \pm 7.1$ & .05 \\
\hline $60-69$ & $6.2 \pm 7.0$ & $7.0 \pm 6.4$ & NS \\
\hline$<60$ & $4.9 \pm 2.2$ & $6.2 \pm 4.4$ & .02 \\
\hline New dialysis & $8(2.1)$ & $22(0.9)$ & .04 \\
\hline New atrial fibrillation & $80(20.6)$ & $511(21.2)$ & NS \\
\hline Reoperative bleeding & $7(1.8)$ & $56(2.3)$ & NS \\
\hline Deep sternal infection & $1(0.3)$ & $14(0.6)$ & NS \\
\hline Prolonged intubation & $10(2.6)$ & $84(3.5)$ & NS \\
\hline Twelve-hour blood loss (mL) & $511 \pm 438$ & $503 \pm 519$ & NS \\
\hline Blood product use $(\%)$ & 57.8 & 57.3 & NS \\
\hline Patients with no complications (\%) & (72) & (70) & NS \\
\hline Readmission 6 weeks & $49(12.6)$ & $306(12.7)$ & NS \\
\hline
\end{tabular}

Variables are expressed as mean $\pm \mathrm{SD}$ or $\mathrm{n}(\%)$. LOS, Length of stay; $N S$, not significant.

grafts per patient between OPCAB and on-pump patients. They reported 2.1 grafts per patient in the OPCAB group versus 3.2 grafts per patient in the on-pump CABG group. This difference was magnified in the high-risk subgroup (1.6 vs 3.1 grafts per patient; $P<.001$ ). In short-term follow-up, there was a trend to increased recurrent angina and need for reinterventional procedures in the OPCAB patients.

Gundry and associates ${ }^{15}$ reported a 7-year follow-up on a cohort of patients having OPCAB from 1989 to 1990, before the current era of commercial stabilizers. They noted twice as many recatheterizations (30\% vs 16\%) and three times the reintervention rate (20\% vs $7 \%$ ) when compared with a group of patients having on-pump CABG. Their patients in the OPCAB group received fewer grafts $(2.4 \pm$ 0.9 vs $3.2 \pm 1.1$ vessels per patient) and a much lower proportion of lateral and inferior wall bypass grafts.

The possibility of incomplete revascularization and early failure resulting from technical difficulties in constructing bypass grafts to the lateral or inferior wall must be considered. Incomplete revascularization was nearly twice as common in our OPCAB patients ( $28.5 \%$ vs $14.6 \%)$. This did not affect early outcomes. However, we may encounter increased recurrent angina and future interventions on continued follow-up.

There are several published series addressing arterial graft patency in OPCAB surgery. They report excellent short-term patency for arterial grafting to the anterior wall. ${ }^{16,17}$ However, angiographic documentation of successful lateral and inferior wall grafting is lacking.

Bhan and coworkers ${ }^{18}$ reported on 96 OPCAB patients who underwent coronary angiography before hospital discharge. They found $97.9 \%$ patency of their LITA to LAD grafts, but they found only $81 \%$ patency of their saphenous vein grafts, which were predominantly placed to lateral and inferior wall bypass targets.

We were expecting to see decreasing morbidity with an off-pump approach. However, our series is notable for a lack of significant differences in postoperative outcomes between OPCAB and on-pump CABG patients. There were no significant differences in mortality or stroke rate. Blood product usage and 12-hour blood loss were not significantly different between on-pump and OPCAB patients, despite differences noted by other groups of less bleeding and blood product usage in OPCAB patients. ${ }^{19}$ Although not followed in our database, the increased bleeding and blood product usage in our series may reflect a selection bias to perform OPCAB on patients we believe have significant bleeding risk (ie, patients with prior thrombolytic and antiplatelet inhibitor use). There were significantly more OPCAB patients with preoperative renal insufficiency. We did not follow postoperative creatinine in our database. However, the incidence of new dialysis was greater in the OPCAB group ( $2.1 \%$ vs $0.9 \% ; P<.04)$.

Our series is similar to others in comparing treatment groups retrospectively adjusted for predicted preoperative risk. However, biases were introduced including less extensive coronary artery disease and fewer bypass grafts in OPCAB patients. A multivariable logistic regression analysis was performed to minimize these biases, but we were unable to demonstrate any negative effect of CPB on shortterm outcomes. Calafiore and associates ${ }^{20}$ reported a series of 1843 patients nearly equally divided between OPCAB and on-pump CABG. They found in a stepwise logistic regression analysis that $\mathrm{CPB}$ was an independent risk factor for higher mortality (odds ratio, 2.2; $P=.0217$ ). 
Randomized multi-institution studies seem to be the only solution to answering the question whether CPB affects outcomes in coronary revascularization.

Can these make a difference? The Bypass Angioplasty Revascularization Investigation (BARI) is a prospective, randomized study comparing balloon angioplasty (PTCA) with conventional $\mathrm{CABG}$ in multivessel coronary artery patients. ${ }^{18-20}$ In BARI, they found significant differences in outcomes for mortality and reintervention rate favoring conventional $\mathrm{CABG}$ for the randomized patient population with diabetes. However, these favorable differences in outcomes for conventional CABG patients who had diabetes disappeared when examining the BARI registry patients who had PTCA. This is because the registry patients were not randomized. They were followed by the BARI investigators, and the decision to undergo PTCA versus CABG was made by the cardiologist. The diabetic registry patients who underwent PTCA tended to have less extensive CAD (ie, more double-vessel disease, less left main and triplevessel disease) than patients referred for CABG. Moreover, unfavorable lesions for PTCA tended to be referred for CABG. It is not hard to imagine that diabetic patients with subjectively better vascular runoff and distal bypass targets were more frequently referred for PTCA. BARI warns us that all nonrandomized comparisons of OPCAB versus onpump CABG will have selection biases, particularly in terms of extent of CAD and quality of distal targets. As we have seen, this may affect the rate of recurrent angina and reinterventions in the future.

In conclusion, our prospective, nonrandomized series comparing OPCAB with on-pump CABG demonstrates that we can select slightly higher risk patients for OPCAB with similar outcomes in the short term. However, a randomized, prospective study with sufficient numbers of elderly, highrisk patients is needed to answer questions of short- and long-term benefit.

\section{References}

1. Cooley DA. Con: Beating-heart surgery for coronary revascularization: Is it the most important development since the introduction of the heart-lung machine? Ann Thorac Surg. 2000;70:1779-81.

2. Kolessov VI. Mammary artery-coronary artery anastomosis as method of treatment for angina pectoris. J Thorac Cardiovasc Surg. 1967;54: $535-44$.

3. O'Connor GT, Plume SK, Olmstead EM, Coffin LH, Morton JR, Maloney CT, et al. Multivariate prediction of in-hospital mortality associated with coronary artery bypass graft surgery. Circulation. 1992;85:2110-8.

4. Blanche C, Matloff JM, Denton TA, Khan SS, DeRobertis MA, Nessim S, et al. Cardiac operations in patients 90 years of age and older. Ann Thorac Surg. 1997;63:1685-90.
5. Tsai TP, Chaux A, Matloff JM, Kass RM, Gray RJ, DeRobertis MA, et al. Ten-year experience of cardiac surgery in patients aged 80 years and over. Ann Thorac Surg. 1994;58:445-51.

6. Tuman KJ, McCarthy RJ, Najafi H, Ivankovich AD. Differential effects of advanced age on neurologic and cardiac risks of coronary artery operations. J Thorac Cardiovasc Surg. 1992;104:1510-17.

7. Newman MF, Kirchner JL, Phillips-Bute B, Gaver V, Grocott H, Jones RH, et al. Longitudinal assessment of neurocognitive function after coronary artery bypass surgery. N Engl J Med. 2001;344:395402.

8. Murkin JM. Neurological outcomes after beating heart coronary artery bypass surgery. From: Salerno TA, Ricci M, Karamanoukian HL, D'ancona G, Bergsland J, editors. Beating heart coronary artery surgery. Armonk (NY): Futura: 2001. p 183-98.

9. Benetti FJ, Naselli G, Wood M, Geffner L. Direct myocardial revascularization without extracorporeal circulation. Experience in 700 patients. Chest. 1991;100:312-6.

10. Buffolo E, De Andrade JCS, Branco JNR, Teles CA, Aguiar LF, Gomes WJ. Coronary artery bypass grafting without cardiopulmonary bypass. Ann Thorac Surg. 1996;61:63-6.

11. Pfister AJ, Zaki MS, Garcia JM, Mispireta LA, Corso PJ, Qazi AG, et al. Coronary artery bypass without cardiopulmonary bypass. Ann Thorac Surg. 1992;54:1085-92.

12. Stamou SC, Dangas G, Dullum MKC, Pfister AJ, Boyce SW, Bafi AS, et al. Beating heart surgery in octogenarians: perioperative outcome and comparison with younger age groups. Ann Thorac Surg. 2000;69: $1140-5$.

13. Ricci M, Karamanoukian HL, Abraham R, Von Fricken K, D'Ancona $\mathrm{G}$, Choi S, et al. Stroke in octogenarians undergoing coronary artery surgery with and without cardiopulmonary bypass. Ann Thorac Surg. 2000;69:1471-5.

14. Arom KV, Flavin TF, Emery RW, Kshettry VR, Janey PA, Petersen RJ. Safety and efficacy of off-pump coronary artery bypass grafting. Ann Thorac Surg. 2000;69:704-10.

15. Gundry SR, Romano MA, Shattuck OH, Razzouk AJ, Bailey LL. Seven-year follow-up of coronary artery bypasses performed with and without cardiopulmonary bypass. J Thorac Cardiovasc Surg. 1998; $115: 1273-8$.

16. Mack MJ, Osborne JA, Shennib H. Arterial graft patency in coronary artery bypass grafting: What do we really know? Ann Thorac Surg. 1998;66:1055-9.

17. Mack MJ, Magovern JA, Acuff TA, Landreneau RJ, Tennison DM, Tinnerman EJ, et al. Results of graft patency by immediate angiography in minimally invasive coronary artery surgery. Ann Thorac Surg. 1999;68:383-90.

18. Bhan A, Choudhary SK, Mathur A, Sharma R, Sahoo M, Agrawal R, et al. Surgical myocardial revascularization without cardiopulmonary bypass. Ann Thorac Surg. 2000;69:1216-21.

19. Nader ND, Khadra WZ, Reich NT, Bacon DR, Salerno TA, Panos AL. Blood product use in cardiac revascularization: comparison of on and off-pump techniques. Ann Thorac Surg. 1999;68:1640-3.

20. Calafiore AM, DiMauro M, Contini M, Di Giammarco G, Pano M, Vitolla G, et al. Myocardial revascularization with and without cardiopulmonary bypass in multivessel disease: impact of the strategy on early outcome. Ann Thorac Surg. 2001;72:456-63.

21. Detre KM, Guo P, Holubkov R, Califf RM, Sopko G, Bach R, et al. Coronary revascularization in diabetic patients. A comparison of the randomized and observational components of the bypass angioplasty revascularization investigation (BARI). Circulation. 1999;99:633-40.

22. The BARI Investigators. Seven-year outcome in the bypass angioplasty revascularization investigation (BARI) by treatment and diabetic status. J Am Coll Cardiol. 2000;35:1122-9.

23. Feit F, Brooks MM, Sopko G, Keller NM, Rosen A, Krone R, et al. Long-term clinical outcome in the Bypass Angioplasty Revascularization Investigation registry: comparison with the randomized trial. Circulation. 2000;101:2795-802. 
Appendix. List and definition of the variables

\begin{tabular}{llll}
\hline Preoperative & & Preoperative & \\
\hline Age & Continuous $(\mathrm{y})$ & Peripheral vascular disease & Dicotomous/indicator \\
Age $\geq 70$ years old & Dicotomous/indicator & Angina (CCS) & Quasi-continuous at 5 levels \\
Sex & Dicotomous/indicator & Congestive heart failure (NYHA) & Quasi-continuous at 5 levels \\
Body surface area & Continuous $\left(\mathrm{m}^{2}\right)$ & Myocardial infarction & Dicotomous/indicator \\
Body mass index & Continuous $\left(\mathrm{kg} / \mathrm{m}^{2}\right)$ & Acute myocardial infarction & Dicotomous/indicator \\
Chronic obstructive pulmonary disease & Dicotomous/indicator & Surgical acuity & Quasi-continuous at 4 levels \\
Diabetes mellitus & Dicotomous/indicator & Cerebrovascular accident & Dicotomous/indicator \\
Creatinine & Continuous & Carotid endarterectomy & Dicotomous/indicator \\
Creatinine $>2.0 \mathrm{mg} / \mathrm{dL}$ & Dicotomous/indicator & Total diseased vessels & Ouasi-continuous at 4 levels \\
Dialysis & Dicotomous/indicator & Circumflex disease & Dicotomous/indicator \\
Ejection fraction & Continuous & Left anterior descending disease & Dicotomous/indicator \\
Ejection fraction $<30 \%$ & Dicotomous/indicator & Left main disease & Dicotomous/indicator \\
Prior CABG & Dicotomous/indicator & Right coronary artery disease & Dicotomous/indicator \\
Prior PTCA & Dicotomous/indicator & Height & Continuous (m) \\
Hypertension & Dicotomous/indicator & Weight & Continuous (kg) \\
Cholesterol & Continuous (mg/dL) & Cardiopulmonary bypass & Dicotomous/indicator
\end{tabular}

CABG, Coronary artery bypass grafting; CCS, Canadian Cardiovascular Society; NYHA, New York Heart Association; PTCA, Percutaneous transluminal coronary angioplasty.

\section{ON THE MOVE?}

Don't miss a single issue of the journal! To ensure prompt service when you change your address, please photocopy and complete the form below.

Please send your change of address notification at least six weeks before your move to ensure continued service. We regret we cannot guarantee replacement of issues missed due to late notification.

\section{JOURNAL TITLE:}

Fill in the title of the journal here.

OLD ADDRESS:

Affix the address label from a recent issue of the journal here.

\section{NEW ADDRESS:}

Clearly print your new address here.

Name

Address

City/State/ZIP

\section{COPY AND MAIL THIS FORM TO:}

Mosby

Subscription Customer Service

6277 Sea Harbor Dr

Orlando, FL 32887
OR FAX TO:

407-363-9661

Mosby
OR PHONE:

800-654-2452

Outside the U.S., call

407-345-4000 